Article

\title{
Production of Thermophilic Chitinase by Paenibacillus sp. TKU052 by Bioprocessing of Chitinous Fishery Wastes and Its Application in $N$-acetyl-D-glucosamine Production
}

\author{
Chien Thang Doan ${ }^{1,2} \mathbb{D}^{-}$, Thi Ngoc Tran ${ }^{1,3}\left[\right.$ and San-Lang Wang ${ }^{2,4, *(1)}$ \\ 1 Faculty of Natural Sciences and Technology, Tay Nguyen University, Buon Ma Thuot 630000, Vietnam; \\ dcthang@ttn.edu.vn (C.T.D.); ttngoc@ttn.edu.vn (T.N.T.) \\ 2 Department of Chemistry, Tamkang University, New Taipei City 25137, Taiwan \\ 3 Doctoral Program in Applied Sciences, College of Science, Tamkang University, \\ New Taipei City 25137, Taiwan \\ 4 Life Science Development Center, Tamkang University, New Taipei City 25137, Taiwan \\ * Correspondence: sabulo@mail.tku.edu.tw; Tel.: +886-2-2621-5656; Fax: +886-2-2620-9924
}

check for updates

Citation: Doan, C.T.; Tran, T.N.; Wang, S.-L. Production of Thermophilic Chitinase by Paenibacillus sp. TKU052 by Bioprocessing of Chitinous Fishery Wastes and Its Application in $\mathrm{N}$-acetyl-D-glucosamine Production. Polymers 2021, 13, 3048. https:// doi.org/10.3390/polym13183048

Academic Editor: Arn Mignon

Received: 18 August 2021

Accepted: 7 September 2021

Published: 9 September 2021

Publisher's Note: MDPI stays neutral with regard to jurisdictional claims in published maps and institutional affiliations.

Copyright: (c) 2021 by the authors. Licensee MDPI, Basel, Switzerland. This article is an open access article distributed under the terms and conditions of the Creative Commons Attribution (CC BY) license (https:// creativecommons.org/licenses/by/ $4.0 /)$.

\begin{abstract}
The bioprocessing of chitinous fishery wastes (CFWs) to chitinases through fermentation approaches has gained importance owing to its great benefits in reducing the enzyme production cost, and utilizing chitin waste. In this work, our study of the chitinase production of Paenibacillus sp. TKU052 in the presence of different kinds of CFWs revealed a preference for demineralized crab shells powder (deCSP); furthermore, a $72 \mathrm{kDa}$ chitinase was isolated from the $0.5 \%$ deCSP-containing medium. The Paenibacillus sp. TKU052 chitinase displayed maximum activity at $70{ }^{\circ} \mathrm{C}$ and $\mathrm{pH} 4-5$, while $\mathrm{Zn}^{2+}, \mathrm{Fe}^{3+}$, Triton X-100, Tween 40, and SDS exerted a negative effect on its activity, whereas $\mathrm{Mn}^{2+}$ and 2-mercaptoethanol were found to potentially enhance the activity. Among various kinds of polysaccharide, Paenibacillus sp. TKU052 chitinase exhibited the best catalytic activity on colloidal chitin (CC) with $\mathrm{K}_{m}=9.75 \mathrm{mg} / \mathrm{mL}$ and $\mathrm{V}_{\max }=2.43 \mu \mathrm{mol} / \mathrm{min}$. The assessment of the hydrolysis of $\mathrm{CC}$ and $\mathrm{N}$-acetyl chitooligosaccharides revealed that Paenibacillus sp. TKU052 chitinase possesses multiple catalytic functions, including exochitinase, endochitinase, and $N$-acetyl- $\beta$-D-glucosaminidase activities. Finally, the combination of Paenibacillus sp. TKU052 chitinase and Streptomyces speibonae TKU048 $N$-acetyl- $\beta$-D-glucosaminidase could efficiently convert CC to $N$-acetyl-D-glucosamine (GlcNAc) with a production yield of $94.35-98.60 \%$ in $12-24 \mathrm{~h}$.
\end{abstract}

Keywords: chitinous fishery wastes; chitinase; crab shells; Paenibacillus; $N$-acetyl-D-glucosamine

\section{Introduction}

Chitin is a linear polysaccharide made of $N$-acetyl-D-glucosamine (GlcNAc) units linked through the $\beta-1,4$-glycosidic linkages [1,2]. In nature, it is the second most abundant polysaccharide after cellulose, and is also a structural constituent of crustacean exoskeletons, squid pens, fungal cell walls, etc. [3,4]. In the fishery industry, a massive amount of chitinous fishery wastes (CFWs) are generated from shrimp shells, crab shells, and squid pens, and may cause serious environmental pollution if they are not utilized effectively [5]. The chitin extraction process from CFWs commonly involves chemical deproteinization (using strong alkalis), demineralization (using strong acids), and bleaching (using oxidants) [6], thereby potentially releasing hazardous and protein-rich wastewater. On the other hand, CFWs mainly contain chitin and proteins, which can directly serve as nutrient components for microbial fermentation [7-10]. This "green technique" has shown great potential owing to the capability of microbes in utilizing CFWs as appropriate C/N sources for producing various metabolites, such as enzymes [11-14], antioxidants [15], enzymes inhibitors [16,17], antimicrobial agents [18], etc. Concurrently, the bioremediation and chitin waste utilization aspects may be resolved through this technique [19]. 
GlcNAc is of interest due to its potential use in the biomedical, pharmaceutical, food, biofuel, and chemical industries [20,21]. It is commonly produced through the enzymatic and chemical hydrolysis of chitin. Compared to chemical methods requiring harsh conditions (concentrated acid and high temperature), the enzymatic methods can be operated in mild conditions, and are thus highly preferred in terms of being environmentally friendly [22]. Chitinases (EC 3.2.2.14) belong to a group of hydrolytic enzymes that catalyze the degradation of chitin by breaking down the $\beta-1,4$-glycosidic linkages between GlcNAc units [23] and have thus received much attention in the production of GlcNAc. The two categories of chitinases based on the mechanism of chitin hydrolysis include endochitinases (EC 3.2.1.14) and exochitinases (EC 3.2.1.52) [2]. While endochitinases randomly break down the $\beta$-1,4-glycosidic linkages of chitin at internal sites to release $N$-acetyl chitooligosaccharides ( $N$-acetyl COSs), exochitinases-further split into two subcategories: chitobiosidases (EC 3.2.1.29) and $N$-acetyl- $\beta$-D-glucosaminidases (EC 3.2.1.30) - act at the endpoint of $N$-acetyl COSs to release (GlcNAc) 2 (chitobiosidases) or GlcNAc ( $N$-acetyl- $\beta$ D-glucosaminidases) [21]. A high yield of GlcNAc can be obtained by hydrolyzing chitin using a combination of different kinds of chitinases [22].

A wide spectrum of organisms exhibits the capacity to produce chitinase, including viruses, bacteria, insects, fungi, plants, and mammals. Among these, chitinases from microorganisms are of high industrial value, thereby attracting interest in the exploitation of their production processes [24]. For chitinase production by microbes, chitin is of considerable importance by serving as a potential carbon and nitrogen $(\mathrm{C} / \mathrm{N})$ source or an enzyme inducer [25]. Accordingly, the nutritional and enzyme-inducing functions of chitin could be excellently replaced by CFWs, which are deemed as cheap and abundantly available chitin sources. The use of CFWs for medium fermentation to produce microbial enzymes has several advantages, such as lower production costs, superior productivity, and simpler techniques [26]. Several previous studies have reported the production of microbial chitinases using different kinds of CFWs, such as shrimp shells [27,28], shrimp heads [21], crab shells [29], and squid pens [12,30,31]. Paenibacillus, a common chitinase-producing bacterial genus, however, has rarely been reported for chitinase production using CFWs, especially crab shells, as the unique source of $\mathrm{C} / \mathrm{N}$. As such, the evaluation of chitinase production by Paenibacillus using this kind of waste is of significant value.

It is of great importance to obtain novel chitinases with a low-cost production process and appropriate characteristics for industrial applications. Therefore, the objective of this study is to produce chitinase by Paenibacillus sp. TKU052 using CFWs, which are cheap materials, as the sole $\mathrm{C} / \mathrm{N}$ source. The CFWs included in this study were shrimp head powder (SHP), demineralized shrimp shell powder (deSSP), demineralized crab shell powder (deCSP), squid pen powder (SPP), and shrimp shell powder (SSP). Furthermore, the obtained chitinase was examined for its valuable biochemical properties. The chitinase produced by Paenibacillus sp. TKU052 was a thermophilic enzyme with multi-functional activities, and thus its potential for saccharification of chitin was assessed. Accordingly, Paenibacillus sp. TKU052 chitinase was combined with Streptomyces speibonae TKU048 N-acetyl- $\beta$-D-glucosaminidase to effectively hydrolyze colloidal chitin (CC) to produce GlcNAc.

\section{Materials and Methods}

\subsection{Materials}

Paenibacillus sp. TKU052 was the same strain as was used in our previous work [9]. Shrimp heads were purchased from Fwu-Sow Industry (Taichung, Taiwan). Crab shells, squid pens, and shrimp shells were purchased from Shin-Ma Frozen Food Co. (I-Lan, Taiwan). The demineralization of shrimp shells and crab shells was described in our previous work [9]. Macro-Prep High S resin was purchased from Bio-Rad (Hercules, CA, USA). Chitin, 75\% DDA (degree of deacetylation) chitosan, GlcNAc, 2-mercaptoethanol (2-ME), ethylenediaminetetraacetic acid (EDTA), $\mathrm{D}_{2} \mathrm{O}$, Congo Red, pectin, starch, xylan, carboxymethyl cellulose, gum arabic, $\beta$-1,3-glucan, dextran and 3,5-dinitrosalicylic acid 
(DNS) were purchased from Sigma (St. Louis, MO, USA). Tween 20, Tween 40, Triton X-100, and SDS were purchased from Merck (Darmstadt, Germany). $\alpha$-chitin powder and $\beta$-chitin powder were purchased from Charming and Beauty Co. (Taipei, Taiwan). Other chemicals used were of the highest possible quality.

\subsection{Chitinase Assay}

The activity of Paenibacillus sp. TKU052 chitinase was determined using CC (1\%) as the substrate. Briefly, $200 \mu \mathrm{L}$ of the reaction solution, consisting of $100 \mu \mathrm{L}$ of CC (prepared in $100 \mathrm{mM}$ sodium acetate buffer, $\mathrm{pH}=5$ ) and $100 \mu \mathrm{L}$ of the enzyme, was incubated at $37{ }^{\circ} \mathrm{C}$ for $30 \mathrm{~min}$. Then, $750 \mu \mathrm{L}$ of DNS reagent was added to the reaction solution, and the mixture was heated at $100{ }^{\circ} \mathrm{C}$ for $10 \mathrm{~min}$. The resulting solution was centrifuged at $13,000 \mathrm{rpm}(10 \mathrm{~min})$ to obtain a clear liquid. Then, $250 \mu \mathrm{L}$ of the liquid was transferred to a 96-well plate and quantified by a microplate reader (Bio-Rad, Hercules, CA, USA) at $515 \mathrm{~nm}$. GlcNAc was used as the reference to calculate the amount of reducing sugar in the sample solution. One chitinase unit is the amount of enzyme that catalyzes the degradation of $\mathrm{CC}$ to liberate $1 \mu \mathrm{M}$ of reducing sugar at $37^{\circ} \mathrm{C}$ in $1 \mathrm{~min}$.

\subsection{Chitinase Production and Purification}

Paenibacillus sp. TKU052 was grown in a culture medium consisting of $0.05 \% \mathrm{MgSO}_{4}$, $0.1 \% \mathrm{~K}_{2} \mathrm{HPO}_{4}$, and $1 \%$ of each CFW type (deCSP, SHP, deSSP, SSP, and SPP) or chitin at the following cultural conditions: culture temperature of $37^{\circ} \mathrm{C}$ and shaking speed of $150 \mathrm{rpm}$. The culture medium was tested for its chitinase activity every $24 \mathrm{~h}$. Different amounts of deCSP, from $0.25 \%$ to $3 \%$, were also used to assess the suitable $\mathrm{C} / \mathrm{N}$ concentration for chitinase production at $37^{\circ} \mathrm{C}$ and $150 \mathrm{rpm}$.

One liter of Paenibacillus sp. TKU052 culture supernatant obtained from 5-day old culture medium was used for purifying the chitinase produced. $\left(\mathrm{NH}_{4}\right)_{2} \mathrm{SO}_{4}$ was added to the supernatant for $60 \%$ saturation, and the mixture was kept at $4{ }^{\circ} \mathrm{C}$ overnight. The precipitate was obtained by centrifugation $\left(4^{\circ} \mathrm{C}, 13,000 \mathrm{rpm}, 30 \mathrm{~min}\right)$, resuspended in $25 \mathrm{mM}$ sodium phosphate buffer $(\mathrm{pH}=5.8)$, dialyzed against a similar buffer, and loaded onto a Macro-Prep High S column. The elution was performed with the $\mathrm{NaCl}$ gradients of 0-0.1 $\mathrm{M}$ and $0.1-1 \mathrm{M}$. The activity fraction was concentrated by means of the freezedrying method and loaded into a Hitachi Chromaster HPLC (High-Performance Liquid Chromatography, Hitachi, Tokyo, Japan) apparatus coupled with KW-802.5 column under the following conditions: solvent: $25 \mathrm{mM}$ sodium phosphate buffer $(\mathrm{pH}=5.8$ ); flow rate: $0.6 \mathrm{~mL} / \mathrm{min}$; sample volume: $50 \mu \mathrm{L}$; column temperature: $20{ }^{\circ} \mathrm{C}$; ultraviolet detector at the wavelength of $280 \mathrm{~nm}$. The molecular weight of the Paenibacillus sp. TKU052 chitinase was determined according to the Laemmli method using a 10\% resolving gel [9]. Zymogram of Paenibacillus sp. TKU052 chitinase was performed on $0.05 \%$ chitin acrylamide gel and using $0.01 \%$ Congo Red as the staining solution [30].

\subsection{Effect of Temperature and $p H$}

The optimum temperature for Paenibacillus sp. TKU052 chitinase was assayed in the range of $30-80{ }^{\circ} \mathrm{C}$. The optimum $\mathrm{pH}$ for the enzyme was assayed in the range of $\mathrm{pH}=3-10$ using various buffers at the same concentration of $50 \mathrm{mM}$. The buffers included $\mathrm{Na}_{2} \mathrm{CO}_{3}-\mathrm{NaHCO}_{3}$ buffer $(\mathrm{pH}=9-10)$, sodium phosphate buffer $(\mathrm{pH}=6-8)$, sodium acetate buffer $(\mathrm{pH}=4-5)$, and glycine- $\mathrm{HCl}$ buffer $(\mathrm{pH}=3)$. The thermal and $\mathrm{pH}$ stabilities of Paenibacillus sp. TKU052 chitinase was based on the residual activity after treating the enzyme at different temperatures or $\mathrm{pH}$ for $1 \mathrm{~h}$. The residual activity was measured at $\mathrm{pH}=5$ and $37^{\circ} \mathrm{C}$ following the method described above.

\subsection{Effect of Various Ions and Chemicals}

Paenibacillus sp. TKU052 chitinase was incubated with various chemicals (including $\mathrm{Fe}^{2+}, \mathrm{Ca}^{2+}, \mathrm{Ba}^{2+}, \mathrm{Mg}^{2+}, \mathrm{Cu}^{2+}, \mathrm{Fe}^{3+}, \mathrm{Zn}^{2+}, \mathrm{EDTA}, 2-\mathrm{ME}$, Tween 20, Tween 40, Triton X-100, and SDS) at $20^{\circ} \mathrm{C}$ for $30 \mathrm{~min}$. The chemicals were tested at a final concentration of $5 \mathrm{mM}$, 
while the surfactants were used at 5\%. The residual activity of Paenibacillus sp. TKU052 chitinase was measured as described above.

\subsection{Substrate Specificity}

This test was performed following the chitinase assay described above, but CC was alternately replaced by $\alpha$-chitin powder, $\beta$-chitin powder, $75 \%$ DDA chitosan, $100 \%$ DDA chitosan, pectin, starch, xylan, carboxymethyl cellulose, gum arabic, $\beta-1,3$-glucan, and dextran. The $\mathrm{K}_{m}$ and $\mathrm{V}_{\max }$ of Paenibacillus sp. TKU052 chitinase were estimated using Lineweaver-Burk plots with a final CC concentration range of $0.5-2.5 \mathrm{mg} / \mathrm{mL}$.

\subsection{The Pattern of Hydrolysis}

$\mathrm{CC}$ and $\mathrm{N}$-acetyl COSs with the degrees of polymerization (DP) $=2-6$ were used as the enzyme substrates to explore the hydrolysis mechanism of Paenibacillus sp. TKU052 chitinase. At different time intervals, the reaction solution was analyzed by the HPLC process described in Section 2.9.

\subsection{Production of GlcNAc}

The reaction solution $(20 \mathrm{~mL})$, consisting of $1 \%$ CC, $100 \mathrm{mM}$ sodium acetate buffer (pH 5), and $10 \mathrm{U} / \mathrm{mL}$ of Paenibacillus sp. TKU052 chitinase or $10 \mathrm{U} / \mathrm{mL}$ of S. speibonae TKU048 $N$-acetyl- $\beta$-D-glucosaminidase or $5 \mathrm{U} / \mathrm{mL}$ of Paenibacillus sp. TKU052 chitinase combined with $5 \mathrm{U} / \mathrm{mL}$ of $S$. speibonae TKU048 $\mathrm{N}$-acetyl- $\beta$-D-glucosaminidase were incubated at $60{ }^{\circ} \mathrm{C}$ and a shaking speed of $150 \mathrm{rpm}$. At different time intervals, $0.2 \mathrm{~mL}$ of the solution was withdrawn to quantify the concentration of GlcNAc and $N$-acetyl COSs by the HPLC method (described in Section 2.9). The GlcNAc yield was calculated using the formula:

$$
\text { GlcNAc yield }=\text { Amount of GlcNAc/Amount of substrate }(\%)
$$

\subsection{HPLC Analysis}

GlcNAc and $N$-acetyl COSs were analyzed by HPLC using a Hitachi Chromaster HPLC apparatus coupled with a KS-802 column under the following conditions: solvent: water; flow rate: $0.6 \mathrm{~mL} / \mathrm{min}$; sample volume: $20 \mu \mathrm{L}$; column temperature: $80^{\circ} \mathrm{C}$; ultraviolet detector at the wavelength of $205 \mathrm{~nm}$.

\subsection{Proton Nuclear Magnetic Resonance $\left({ }^{1} H-N M R\right)$ Analysis}

${ }^{1} \mathrm{H}-\mathrm{NMR}$ analysis was performed using a Bruker 600 Ultrashield NMR spectrophotometer (Bruker, New Taipei City, Taiwan). The solvent used was $\mathrm{D}_{2} \mathrm{O}$ and the chemical shifts are shown in ppm (parts per million).

\section{Results and Discussion}

\subsection{Chitinase Production}

Paenibacillus sp. TKU052 was isolated from the soil of Tamkang University using SPP-containing medium and was found to be closely related to P. tyrfis MSt1 (99.3\%) and P. elgii SD17 (99.3\%) according to 16S rDNA partial base sequence analysis [9]. In the current work, Paenibacillus sp. TKU052 created a zone of hydrolysis on the CC plate after three days of incubation (Figure 1), indicating that this strain secretes extracellular chitinolytic enzymes to degrade the surrounding CC. The chitinase-producing ability of P. elgii and P. tyrfis species is rarely reported [32,33]. More so, none of these species have been evaluated for their chitinase production on a medium containing CFWs and the application of their enzymes in GlcNAc production. As such, this work may provide an insight into the conversion of CFWs to produce chitinase by Paenibacillus sp. TKU052 strain, as well as the biochemical properties and the application of the obtained chitinase in GlcNAc production. 


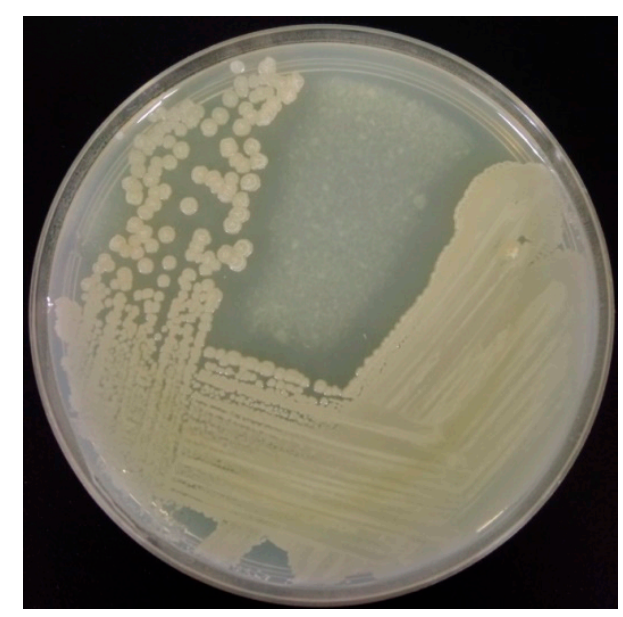

Figure 1. The chitinase-producing ability of Paenibacillus sp. TKU052 on CC agar medium.

The chitinase production of Paenibacillus sp TKU052 on a medium containing CFWs as the unique $\mathrm{C} / \mathrm{N}$ source was explored. The chitinous materials used were deCSP, deSSP, SPP, SHP, SSP, and chitin. In addition, nutrient broth, a non-chitinous medium, was also used to test the enzyme productivity of Paenibacillus sp TKU052. As shown in Figure 2a, the maximal chitinase activity of deCSP-supplemented medium was 0.53 (day 5), 0.55 (day 6), and $0.55 \mathrm{U} / \mathrm{mL}$ (day 7), that of deSSP-supplemented medium was $0.32 \mathrm{U} / \mathrm{mL}$ (day 7); that of SPP-supplemented medium was $0.29 \mathrm{U} / \mathrm{mL}$ (day 4); that of SHP-supplemented medium was $0.30 \mathrm{U} / \mathrm{mL}$ (day 4); that of SSP-supplemented medium was $0.29 \mathrm{U} / \mathrm{mL}$ (day 5); that of chitin-supplemented medium was $0.36 \mathrm{U} / \mathrm{mL}$ (day 7); and finally, that of nutrient broth medium was 0.07 (day 4) and $0.06 \mathrm{U} / \mathrm{mL}$ (day 5). According to the result, Paenibacillus sp. TKU052 exhibited higher chitinase productivity toward chitin-containing media, suggesting that chitin may be a key factor for chitinase production by Paenibacillus sp. TKU052. Among those, the highest chitinase productivity of Paenibacillus sp. TKU052 was found in the deCSP-supplemented medium. Chitin, especially in colloidal form, is a widely used supplement to the chitinase-producing medium as an inducer or a nutrient source. Chemical treatment is a mandatory step to produce chitin from chitinous materials, thereby possibly leading to environmental pollution and increased production cost of the processes using chitin [34,35]. Therefore, CFWs are being assessed as an effective alternative for the cost-effective production of microbial chitinases. In addition, the use of chitinous wastes for the production of microbial chitinases by various bioprocesses is regarded as being a significant part of the utilization of these waste sources. In this study, deCSP exhibited good results and was chosen as the best $\mathrm{C} / \mathrm{N}$ source for chitinase production by Paenibacillus $\mathrm{sp}$. TKU052 and further analyses.

The effect of the deCSP amount on chitinase productivity of Paenibacillus sp. TKU052 was examined over a range of $0.25-3 \%$, and the results are shown in Figure $2 \mathrm{~b}$. The maximal chitinase activity of $0.25 \%$ deCSP-supplemented medium was $0.43 \mathrm{U} / \mathrm{mL}$ (day 5); of $0.5 \%$ deCSP-supplemented medium was $0.59 \mathrm{U} / \mathrm{mL}$ (day 5); that of $1 \%$ deCSP-supplemented medium was $0.54 \mathrm{U} / \mathrm{mL}$ (day 5); that of $2 \%$ deCSP-supplemented medium was $0.47 \mathrm{U} / \mathrm{mL}$ (day 7); and that of $3 \%$ deCSP-supplemented medium was $0.26 \mathrm{U} / \mathrm{mL}$ (day 6). The results indicate that $0.5 \%$ deCSP is the most appropriate $\mathrm{C} / \mathrm{N}$ amount for chitinase production by Paenibacillus sp. TKU052.

With its abundance, wasted crab shell is of interest for the preparation of various bioactive compounds, such as chitin, protease, prodigiosin, antioxidant, antidiabetic and anticancer agents $[9,36]$. In this study, this kind of CFW was also found to be the best C/N source for chitinase production by Paenibacillus sp. TKU052. 


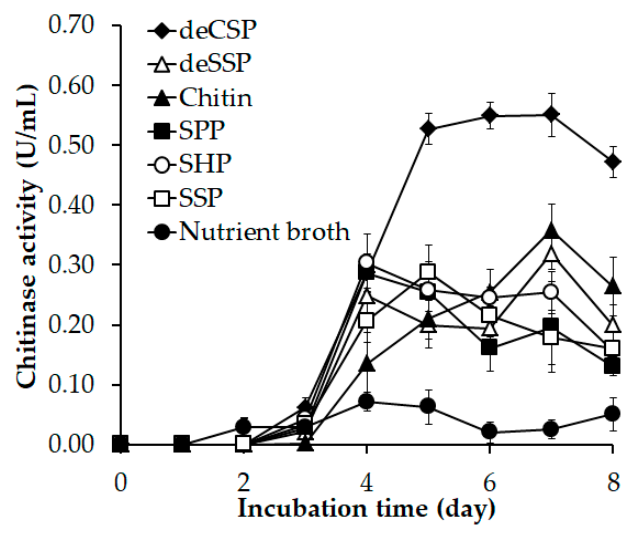

(a)

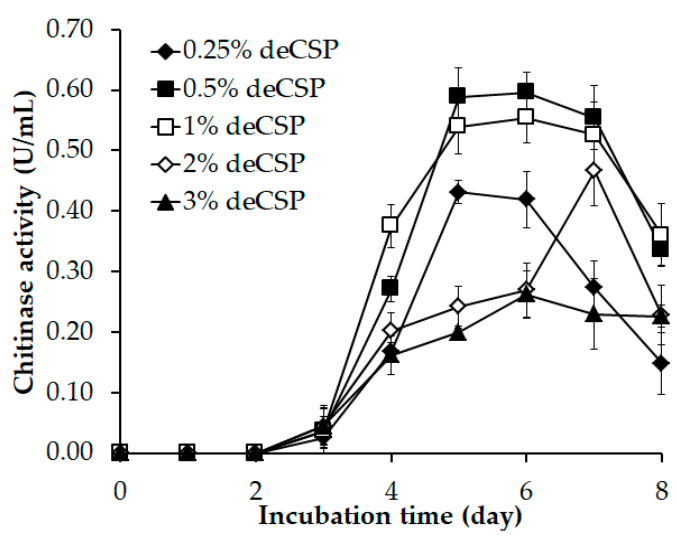

(b)

Figure 2. Screening of suitable $\mathrm{C} / \mathrm{N}$ source for chitinase production by Paenibacillus sp. TKU052: (a) different kinds of CFWs and (b) different amounts of deCSP were examined. The error bar is the standard deviation of three replicates.

\subsection{Chitinase Purification}

The supernatant of a 5-day old culture of Paenibacillus sp. TKU052 grown using $0.5 \%$ deCSP-supplemented medium was obtained by centrifugation. Chitinase in the supernatant was purified as follows: $60 \%\left(\mathrm{NH}_{4}\right)_{2} \mathrm{SO}_{4}$ precipitation, cation exchange chromatography using Macro-Prep High S resin, and size exclusion chromatography using HPLC coupling with KW-802.5 column. The crude enzyme was loaded onto a Macro-Prep High $\mathrm{S}$ column equilibrated by sodium phosphate buffer $(25 \mathrm{mM}, \mathrm{pH}=5.8)$. According to the enzyme elution profile, only one chitinase peak was eluted at $10-70 \mathrm{mM} \mathrm{NaCl}$ (fractions 129-166) (Figure 3a). The HPLC profile of the chitinase fraction obtained from cation exchange chromatography is shown in Figure $3 b$. The fraction containing the chitinase activity was eluted at a retention time of $13.3 \mathrm{~min}$. The fractions that exhibited the chitinase activity were pooled and analyzed by the HPLC system using a KW-802.5 column. Accordingly, only one protein peak at a retention time of $13.3 \mathrm{~min}$ was observed, suggesting that the obtained chitinase was homogeneous (Figure 3c). The result of the purification of Paenibacillus sp. TKU052 chitinase is summarized in Table 1. Enzyme purity was estimated to be 19.47-fold greater than that of the cultural supernatant. The purified chitinase had a specific activity of $2.55 \mathrm{U} / \mathrm{mg}$, with a yield of about $4.01 \%$.

The homogeneity of the purified chitinase was also examined by SDS-PAGE and chitin zymography. A unique protein band (Figure 4a) and chitinolytic band (Figure $4 \mathrm{~b}$ ) at $72 \mathrm{kDa}$ were observed for the purified chitinase indicating that the Paenibacillus sp. TKU052 chitinase has a molecule weight (MW) of $72 \mathrm{kDa}$. The MW of Paenibacillus sp. TKU052 chitinase is similar to that of chitinases/chitosanases from P. barengoltzii (74.6 kDa) [2], P. ehimensis MA2012 (>100, 100, 72, 65, 60, 50, 37, and $35 \mathrm{kDa)} \mathrm{[37],} \mathrm{P.} \mathrm{timonensis} \mathrm{LK-DZ15}$ (70 kDa) [38], P. pasadennesis CS0611 (69 kDa) [39], P. elgii HOA73 (68 kDa) [33], Paenibacillus sp. TKU042 (70 kDa) [35], but much higher than that from Paenibacillus sp. TKU047 (23 kDa) [30], P. thermoaerophilus TC22-2b (48 kDa) [40], P. dendritiformis (31 kDa) [41], P. macerans TKU029 (63 kDa) [42], and P. pasadenensis NCIM 5434 (35 kDa) [43]. Generally, the MW of chitinases/chitosanases from Paenibacillus species is in the range of 30-70 kDa [30]. 


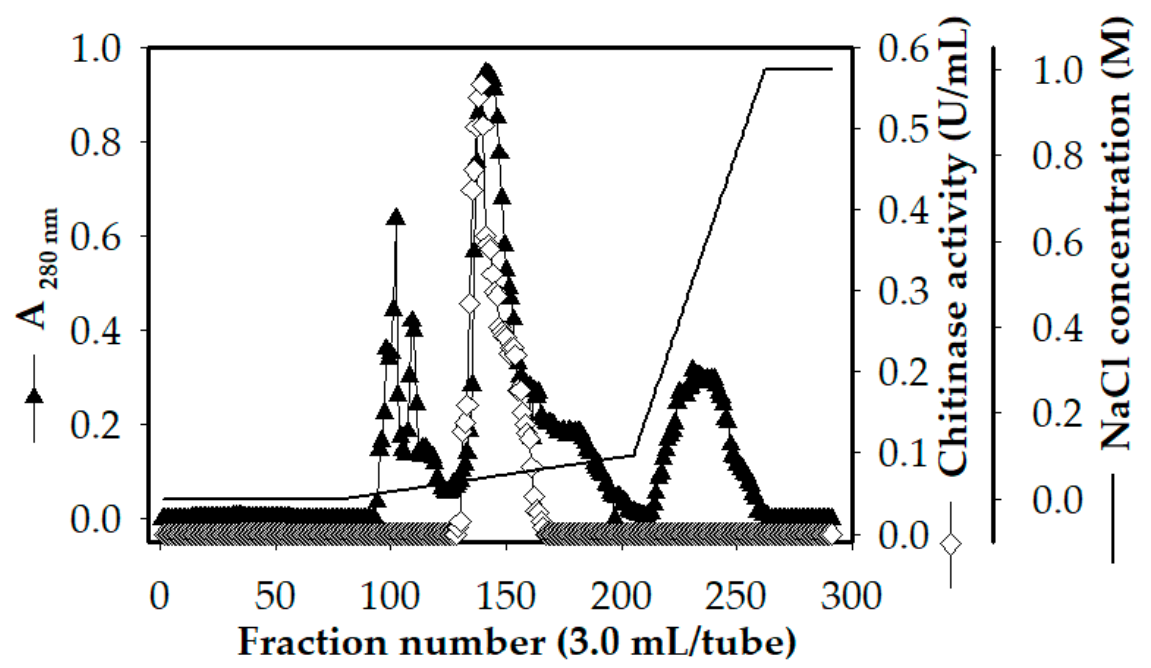

(a)

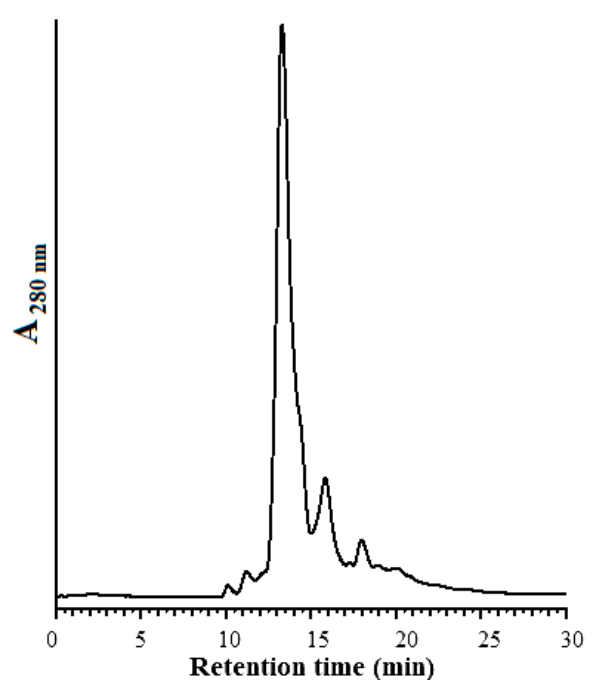

(b)

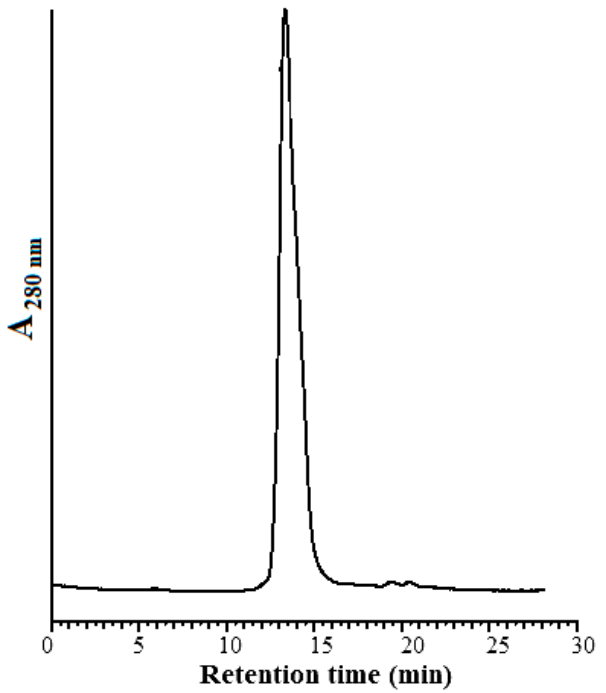

(c)

Figure 3. A typical cation exchange chromatography profile of the crude enzyme obtained from the supernatant of Paenibacillus sp. TKU052 culture medium supplemented with $0.5 \%$ deCSP (a); HPLC profiles of chitinase fraction obtained from the cation exchange chromatography step (b) and the HPLC step (c).

Table 1. A summary of the purification of Paenibacillus sp. TKU052 chitinase.

\begin{tabular}{cccccc}
\hline Step & Total Protein (mg) & Total Activity (U) & $\begin{array}{c}\text { Specific Activity } \\
\text { (U/mg) }\end{array}$ & Recovery (\%) & Purification (Fold) \\
\hline $\begin{array}{c}\text { Cultural supernatant } \\
\left(\mathrm{NH}_{4}\right)_{2} \mathrm{SO}_{4}\end{array}$ & 2731.95 & 358.00 & 0.13 & 100.00 & 1.00 \\
precipitation & 395.94 & 164.40 & 0.42 & 45.92 & 3.17 \\
Macro-Prep High S & 39.67 & 43.56 & 1.10 & 12.17 & 8.38 \\
KW-802.5 & 5.63 & 14.36 & 2.55 & 4.01 & 19.47 \\
\hline
\end{tabular}




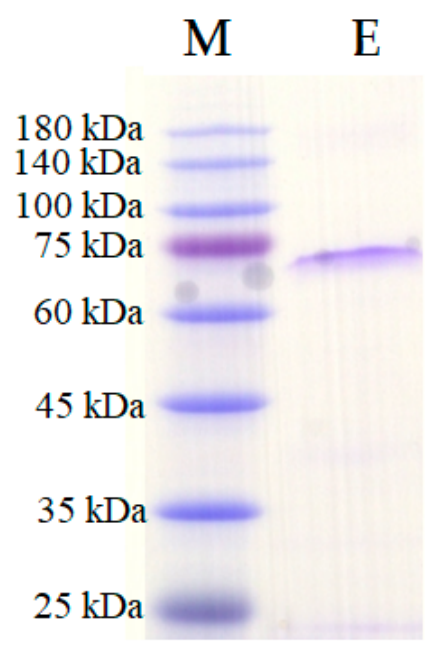

(a)

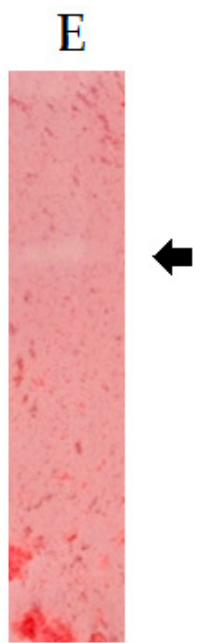

(b)

Figure 4. SDS-PAGE (a) and chitin zymography (b) profile of Paenibacillus sp. TKU052 chitinase. M, protein markers; E, the purified enzyme. The arrow indicates the enzyme location.

\subsection{Effect of Temperature and $p H$}

The temperature was applied in the range of $30-80{ }^{\circ} \mathrm{C}$ to explore the influence of temperature on Paenibacillus sp. TKU052 chitinase activity. The optimal temperature of Paenibacillus sp. TKU052 chitinase was found to be $70{ }^{\circ} \mathrm{C}$ and it was stable up to $60{ }^{\circ} \mathrm{C}$ (Figure 5a). Due to the outstanding functioning at temperatures $\geq 50{ }^{\circ} \mathrm{C}$, Paenibacillus sp. TKU052 chitinase could be categorized as a thermophilic enzyme. By far, thermophilic chitinolytic enzymes have gained the most attention as they can tolerate and act at elevated temperatures. The reaction at a high temperature can provide the benefits of enhancing the solubility/dispersibility of compounds and preventing microbial contamination [44]. The thermophilic enzymes have been examined for various aspects, including the source of the enzyme, the hydrolysis mechanism of the enzyme at a high temperature, genetic engineering, and industrial applications. Accordingly, several Paenibacillus species strains have been found to be capable of producing thermophilic chitinolytic enzymes, with promising potential in the production of chitooligosaccharides and GlcNAc, such as P. barengoltzii chitinase [2], P. thermoaerphilus TC22-2b chitinase [40], P. mucilaginosus TKU032 chitosanase [45], and Paenibacillus sp. 1794 chitosanase [46]. In this study, Paenibacillus sp. TKU052 chitinase exhibited a comparable or even better thermal stability and thermal activity than most of Paenibacillus chitinases/chitosanases $[1,33,40,46,47]$, indicating that this enzyme may be useful for applications in which a thermophilic chitinase is prioritized.

The influence of $\mathrm{pH}$ on the activity of Paenibacillus sp. TKU052 chitinase is shown in Figure 5b. The maximal activity of the enzyme was observed within the $\mathrm{pH}$ range of 4-5, and it was stable within the $\mathrm{pH}$ range of 4-6, suggesting that Paenibacillus sp. TKU052 chitinase is an acidic chitinase. Likewise, several chitinolytic enzymes from Paenibacillus species are functional in acidic conditions, such as $P$. thermoaerophilus TC22-2b. $(\mathrm{pH}=4)$ [40], P. mucilaginosus TKU032 ( $\mathrm{pH}=6)$ [45], Paenibacillus sp. 1794 ( $\mathrm{pH}=4.8)$ [46], P. illinoisensis KJA-424 ( $\mathrm{pH}=5)$ [48], P. timonensis LK-DZ15 $(\mathrm{pH}=4.5)$ [38], P. pasadenensis CS0611 ( $\mathrm{pH}=5$ ) [39], P. barengoltzii CAU904 ( $\mathrm{pH}=3.5)$ [49], Paenibacillus sp. D1 ( $\mathrm{pH}=5)$ [50], and Paenibacillus sp. BISR-047 ( $\mathrm{pH}=5)$ [51]. However, some chitinolytic enzymes from Paenibacillus species have their optimum $\mathrm{pH}$ at neutral and alkaline conditions [30,33,41,42]. Due to its $\mathrm{pH}$ stability and acidic $\mathrm{pH}$ optimum, Paenibacillus sp. TKU052 chitinase could be useful for the applications set up in acidic conditions. 


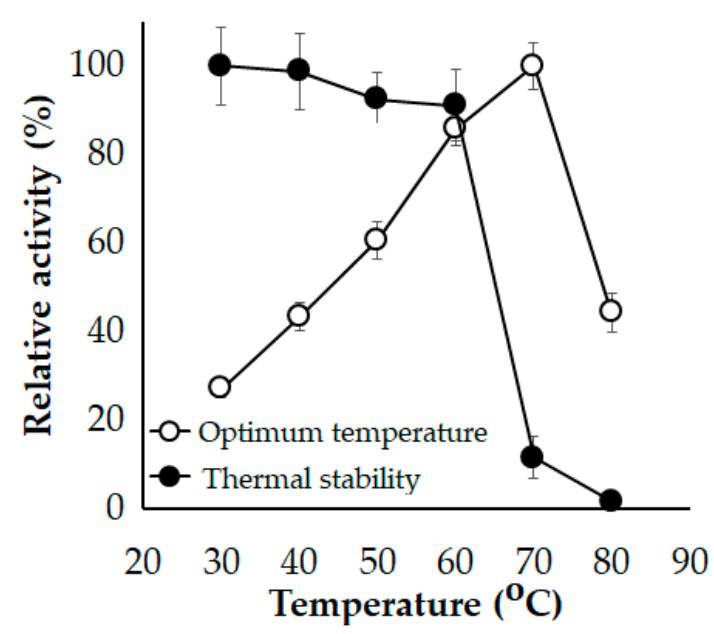

(a)

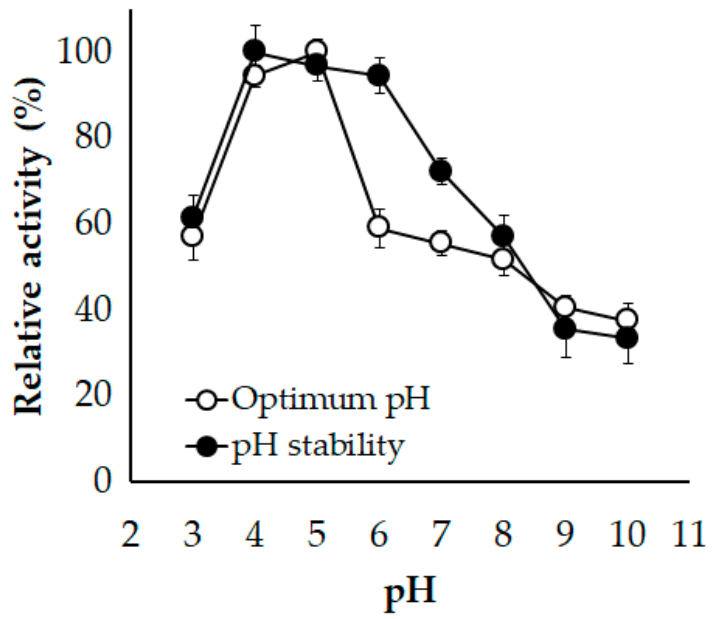

(b)

Figure 5. Effect of temperature (a) and $\mathrm{pH}(\mathbf{b})$ on the activity of Paenibacillus sp. TKU052 chitinase. The error bar is the standard deviation of three replicates.

\subsection{Effect of Various Ions and Chemicals}

The activity of Paenibacillus sp. TKU052 chitinase incubated with various chemicals was examined, and the results are shown in Table 2. Among the metal ions, $\mathrm{Fe}^{2+}, \mathrm{Ca}^{2+}$, $\mathrm{Ba}^{2+}, \mathrm{Mg}^{2+}, \mathrm{Cu}^{2+}$ did not significantly affect the activity of Paenibacillus sp. TKU052 chitinase, while $\mathrm{Fe}^{3+}$ and $\mathrm{Zn}^{2+}$ showed an inhibitory effect by reducing the enzyme activity to $26.72 \%$ and $59.51 \%$, respectively, of its initial activity. The negative effect of heavy metal ions may be due to their ability to destroy the tertiary structure of the protein, thereby inactivating the enzyme [1]. In contrast, $\mathrm{Mn}^{2+}$ showed an enhancing effect on the activity of Paenibacillus sp. TKU052 chitinase (relative activity of $142.57 \%$ ), similar to its positive effect on P. chitinolyticus UMBR 0002 chitinase [1] and Paenibacillus sp. TKU047 chitosanase [30]. Surfactants such as SDS, Triton X-100, and Tween 40 showed a negative effect on Paenibacillus sp. TKU052 chitinase (relative activity of $28.84 \%, 78.96 \%$, and $65.71 \%$, respectively), whereas Tween 20 did not have a significant effect. Paenibacillus sp. TKU052 chitinase was not significantly affected by EDTA, a metal ion chelator, indicating that the activity of the enzyme is not dependent on metal ions. Interestingly, in the presence of 2-ME, the activity of Paenibacillus sp. TKU052 chitinase significantly increased to $129.70 \%$ of its initial activity, demonstrating that cysteine residues are not involved in the formation of its catalytic center [52]. Earlier studies have reported strong inhibition of several chitinases by 2-ME, such as ChiA-Pt70 from P. timonensis LK-DZ15 [38] and CHI from P. chitinolyticus UMBR 0002 [1]. 
Table 2. Effect of various chemicals on the activity of Paenibacillus sp. TKU052 chitinase.

\begin{tabular}{cc}
\hline Chemical & Relative Activity (\%) \\
\hline None & $100.00 \pm 7.23$ \\
$\mathrm{Fe}^{2+}$ & $102.31 \pm 3.85$ \\
$\mathrm{Fe}^{3+}$ & $26.72 \pm 4.12$ \\
$\mathrm{Ca}^{2+}$ & $102.13 \pm 6.37$ \\
$\mathrm{Ba}^{2+}$ & $107.57 \pm 3.12$ \\
$\mathrm{Mn}^{2+}$ & $142.57 \pm 5.02$ \\
$\mathrm{Mg}^{2+}$ & $102.65 \pm 2.18$ \\
$\mathrm{Cu}^{2+}$ & $109.93 \pm 6.82$ \\
$\mathrm{Zn}^{2+}$ & $59.51 \pm 4.30$ \\
$\mathrm{SDS}$ & $28.84 \pm 3.30$ \\
Triton X-100 & $78.96 \pm 7.48$ \\
Tween 40 & $65.71 \pm 11.06$ \\
Tween 20 & $101.16 \pm 12.15$ \\
EDTA & $108.69 \pm 7.21$ \\
2-ME & $129.70 \pm 5.45$ \\
\hline
\end{tabular}

The data are presented as mean \pm standard deviation.

\subsection{Substrate Specificity}

Paenibacillus sp. TKU052 chitinase exhibited the highest relative activity towards CC $(100.00 \%)$, followed by $\beta$-chitin powder $(16.20 \%), 75 \%$ DDA chitosan $(8.64 \%)$, and $\alpha$-chitin powder $(6.65 \%)$ and no activity towards other polysaccharide substrates (Table 3$)$. This result indicates that the activity of Paenibacillus sp. TKU052 chitinase is specific to the linkages of GlcNAc-GlcNAc. Likewise, a similar phenomenon was observed earlier in chitinases from P. chitinolyticus UMBR 0002 [1], P. barengoltzii CAU904 [49], and P. elgii HOA73 [33]. In addition, the physical form of chitin significantly affected the activity of Paenibacillus sp. TKU052 chitinase, wherein the colloidal form of chitin was the most suitable substrate, followed by $\beta$-chitin powder and $\alpha$-chitin powder. Most Paenibacillus chitinases exhibit the highest chitinolytic activity on CC; however, PeChi68, a chitinase from P. elgii HOA73, was reported to prefer chitin powder over CC [33]. Finally, the kinetic parameters $\left(\mathrm{K}_{m}\right.$ and $\left.\mathrm{V}_{\max }\right)$ of Paenibacillus sp. TKU052 chitinase toward CC was estimated to be $9.75 \mathrm{mg} / \mathrm{mL}$ and $2.43 \mu \mathrm{mol} / \mathrm{min}$, respectively.

Table 3. The activity of Paenibacillus sp. TKU052 chitinase on different kinds of substrates.

\begin{tabular}{cc}
\hline Substrate & Relative Activity (\%) \\
\hline CC & $100.00 \pm 8.37$ \\
$\alpha$-chitin powder & $6.65 \pm 0.48$ \\
$\beta$-chitin powder & $16.20 \pm 6.36$ \\
$75 \%$ DDA chitosan & $8.64 \pm 4.46$ \\
$100 \%$ DDA chitosan & N.A. \\
Pectin & N.A. \\
Starch & N.A. \\
Xylan & N.A. \\
Carboxymethyl cellulose & N.A. \\
Gum arabic & N.A. \\
$\beta-1,3$-glucan & N.A. \\
Dextran & N.A \\
\hline
\end{tabular}

N.A., no activity. The data are presented as mean \pm standard deviation.

\subsection{Hydrolysis Pattern}

To explore the hydrolysis mechanism of Paenibacillus sp. TKU052 chitinase, CC and $\mathrm{N}$-acetyl COSs (DP $=2-6$ ) were used as the enzyme substrates. The results are shown in Figure 6. During the first stage (0-6 h), Paenibacillus sp. TKU052 chitinase hydrolyzed CC to yield (GlcNAc) ${ }_{2}$ and GlcNAc, with (GlcNAc) 2 being the most produced product. This 
indicates that Paenibacillus sp. TKU052 chitinase is an exochitinase. From $24 \mathrm{~h}$ onwards, the (GlcNAc) $)_{2}$ gradually decreased over time along with the accumulation of GlcNAc, indicating a clear outcome of the hydrolysis of $(\mathrm{GlcNAc})_{2}$ to form GlcNAc, which means Paenibacillus sp. TKU052 chitinase also possesses $N$-acetyl- $\beta$-D-glucosaminidase activity. However, the hydrolysis of (GlcNAc) $)_{2}$ to form GlcNAc of Paenibacillus sp. TKU052 chitinase was slow and incomplete, despite the extension of the incubation time (up to $96 \mathrm{~h}$ ), indicating a poor $N$-acetyl- $\beta$-D-glucosaminidase activity of Paenibacillus sp. TKU052 chitinase. In addition, a trace peak of (GlcNAc) $)_{3}$ was detected after $0.1 \mathrm{~h}$ of the reaction time, suggesting that Paenibacillus sp. TKU052 chitinase may have some endochitinase activity. The decrease in the (GlcNAc) $)_{3}$ peak also indicates that the generated (GlcNAc) 3 was further degraded by Paenibacillus sp. TKU052 chitinase. The hydrolysis mechanism of Paenibacillus sp. TKU052 chitinase on $\mathrm{N}$-acetyl COSs is presented in Figure 6b. Paenibacillus sp. TKU052 chitinase degrades (GlcNAc) 2 slowly to form GlcNAc, indicating its poor $N$-acetyl- $\beta$-D-glucosaminidase activity, while it could rapidly degrade (GlcNAc) ${ }_{3}$, $(\mathrm{GlcNAc})_{4},(\mathrm{GlcNAc})_{5}$, and (GlcNAc) 6 to form (GlcNAc) 2 and GlcNAc, which confirms that it is an exochitinase. In addition, Paenibacillus sp. TKU052 chitinase rapidly degraded $(\mathrm{GlcNAc})_{4}$ to form (GlcNAc) $)_{2}$, indicating that it could cleave (GlcNAc) $)_{4}$ at the second glycosidic linkage. Paenibacillus sp. TKU052 chitinase could also rapidly degrade (GlcNAc) to form (GlcNAc) $)_{3}$ and $(\mathrm{GlcNAc})_{2}$, and could degrade (GlcNAc) $)_{6}$ to form (GlcNAc) ${ }_{4}$, $(\mathrm{GlcNAc})_{3}$, and (GlcNAc) $)_{2}$, indicating that it cleaved these oligomers at the second and third glycosidic linkages. These results confirm that Paenibacillus sp. TKU052 chitinase may have both exochitinase and endochitinase properties. The hydrolysis mechanism of Paenibacillus sp. TKU052 chitinase is different from chitinases produced by P. barengoltzii [53], S. speibonae TKU048 [20], and P. chitinolyticus UMBR 0002 [1] but similar to those from Chitinolyticbacter meiyuanensis SYBC-H1 (CmChi1), which has been efficiently used to prepare GlcNAc from CC [5]. In conclusion, the result suggests that Paenibacillus sp. TKU052 chitinase may be a multi-functional chitinase, having exochitinase, endochitinase, and $N$-acetyl- $\beta$-D-glucosaminidase activities.

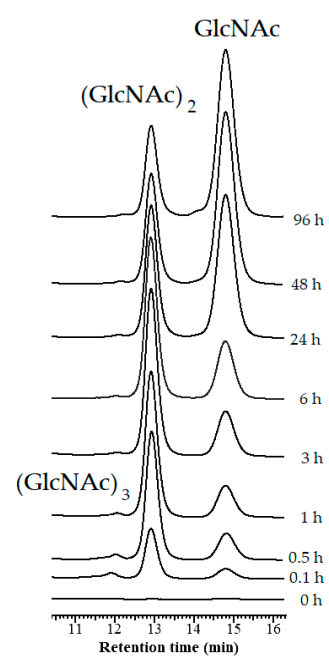

(a)

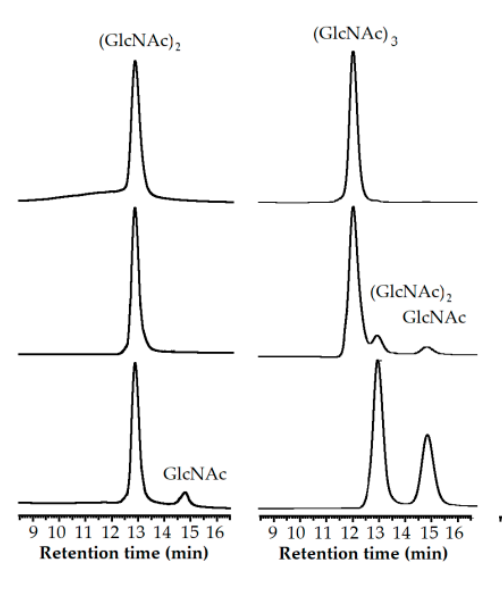

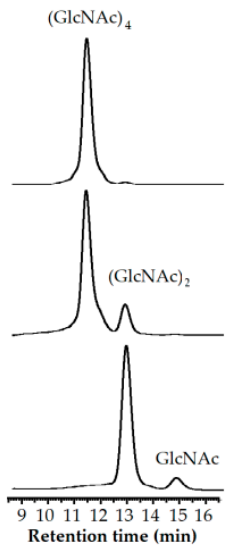
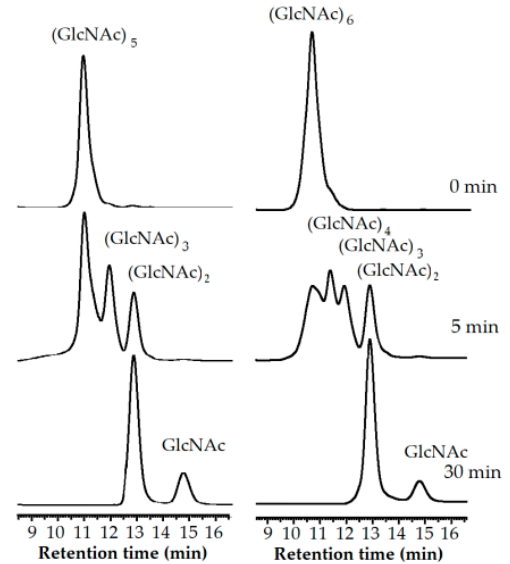

(b)

Figure 6. Hydrolysis pattern of Paenibacillus sp. TKU052 chitinase toward colloidal chitin (CC) (a) and N-acetyl COSs (b).

\subsection{GlcNAc Production}

The synergy between chitinase with both exochitinase and endochitinase activities and $N$-acetyl- $\beta$-D-glucosaminidase may be required for the complete degradation of chitin to GlcNAc [20]. According to the previous experiment, Paenibacillus sp. TKU052 chitinase could rapidly degrade CC to form (GlcNAc) $)_{2}$ and GlcNAc. As a result, this enzyme can effectively assist the $N$-acetyl- $\beta$-D-glucosaminidases to hydrolyze chitin and produce 
GlcNAc. In this study, we used a combination of Paenibacillus sp. TKU052 chitinase and S. speibonae TKU048 $N$-acetyl- $\beta$-D-glucosaminidase to assess the possibility of producing GlcNAc from CC. The products of the hydrolysis process were analyzed by the HPLC method, and the results are presented in Figure 7. In the first hour, GlcNAc and (GlcNAc) were generated at the concentrations of 3.44 and $2.58 \mathrm{mg} / \mathrm{mL}$, respectively. In the next few hours, the concentration of (GlcNAc) $)_{2}$ significantly decreased and reduced to zero after $12 \mathrm{~h}$, whereas the concentration of GlcNAc gradually increased over time and reached its maximum value after $24 \mathrm{~h}(9.86 \mathrm{mg} / \mathrm{mL})$. According to the estimates, the GlcNAc production process could achieve a yield of $98.60 \%$ within a reaction time of $24 \mathrm{~h}$. In addition, $9.44 \mathrm{mg} / \mathrm{mL}$ of GlcNAc, indicating a production yield of $94.35 \%$, without $\mathrm{N}$ acetyl COSs could be observed after a reaction time of $12 \mathrm{~h}$. In addition, we also explored the hydrolysis processes of CC using Paenibacillus sp. TKU052 chitinase and S. speibonae TKU048 N-acetyl- $\beta$-D-glucosaminidase separately. Paenibacillus sp. TKU052 chitinase could not completely degrade (GlcNAc) ${ }_{2}$, and the reaction solution still contained both $(\mathrm{GlcNAc})_{2}$ and GlcNAc at 0.83 and $9.03 \mathrm{mg} / \mathrm{mL}$ concentrations, respectively, (after $240 \mathrm{~h}$ ). In the case of $S$. speibonae TKU048 $N$-acetyl- $\beta$-D-glucosaminidase, $6.10 \mathrm{mg} / \mathrm{mL}$ of GlcNAc without $\mathrm{N}$-acetyl COSs was obtained from the CC hydrolysis with a $60.99 \%$ yield after $96 \mathrm{~h}$. This indicates that a novel combination of Paenibacillus sp. TKU052 chitinase and S. speibonae TKU048 $N$-acetyl- $\beta$-D-glucosaminidase could efficiently improve the GlcNAc production from CC. The efficiency of the present process was compared with those in earlier reports (Table 4). Among them, the combination of Paenibacillus sp. TKU052 chitinase and S. speibonae TKU048 $N$-acetyl- $\beta$-D-glucosaminidase reveals a comparable result with a short required reaction time (12-24 h) and high GlcNAc production yield (94.35-98.60\%). In addition, the absence of $N$-acetyl COSs in the final reaction solution could also simplify the GlcNAc purification step. In this study, GlcNAc was obtained from the chitin hydrolysate solution by one-step purification using HPLC coupled with a KS-802 column. The HPLC result revealed only one peak at a retention time of $14.7 \mathrm{~min}$ (Figure 8a), indicating that the molecular weight of the product is similar to that of the GlcNAc standard. The obtained GlcNAc was analyzed by ${ }^{1} \mathrm{H}-\mathrm{NMR}$ spectroscopy, and as shown in Figure 8b, the obtained GlcNAc had a similar ${ }^{1} \mathrm{H}-\mathrm{NMR}$ profile as that of the profile of commercial GlcNAc from Sigma (St. Louis, MO, USA), confirming the purity of the product. This result, therefore, provides a promising enzymatic method for the production of GlcNAc from CC.

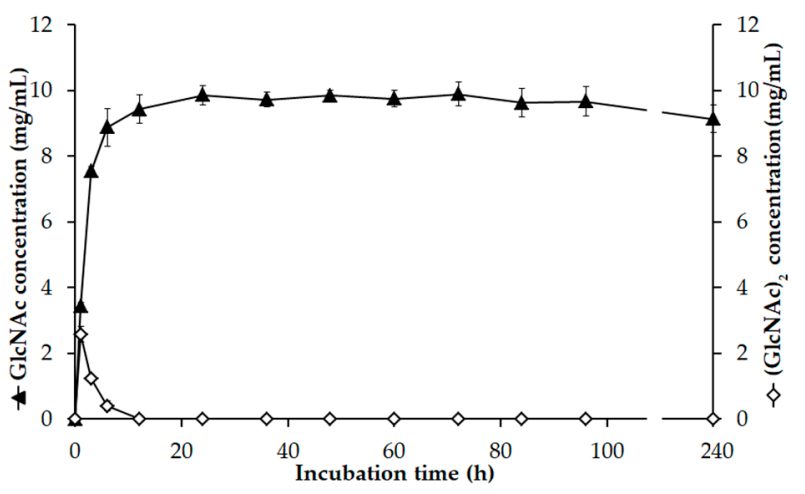

(a)

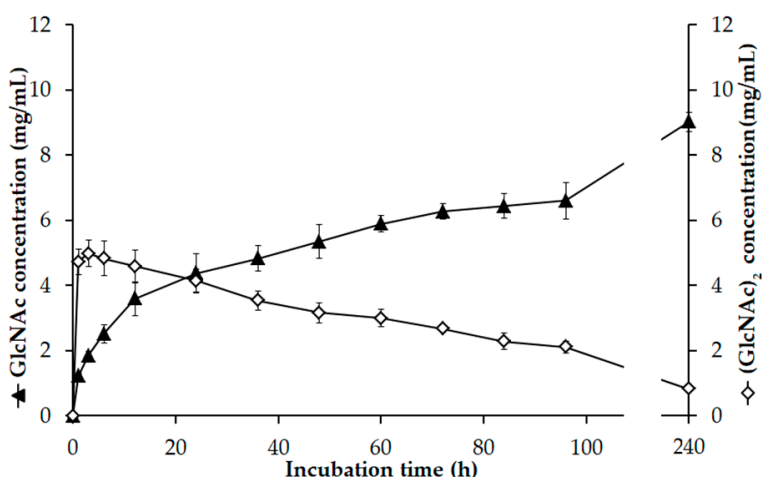

(b)

Figure 7. Cont. 


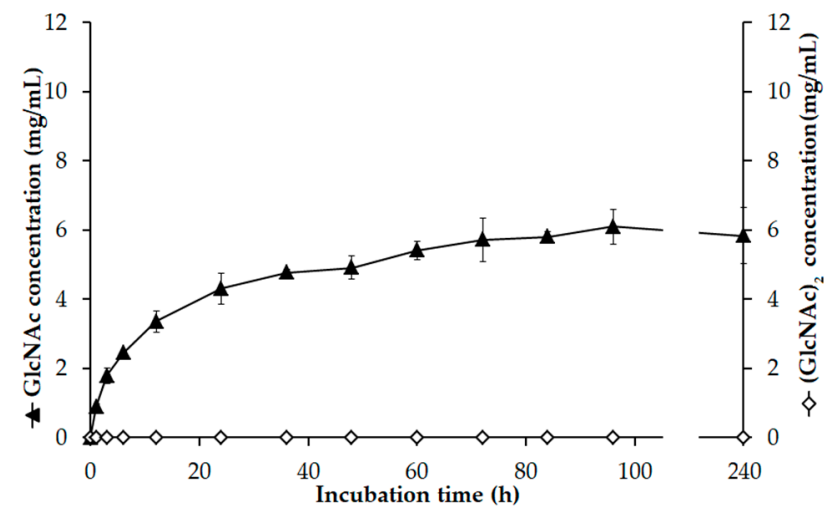

(c)

Figure 7. Time courses of GlcNAc and (GlcNAc) 2 production generated from the hydrolysis of colloidal chitin (CC) catalyzed by a mixture of Paenibacillus sp. TKU052 chitinase and Streptomyces speibonae TKU048 N-acetyl- $\beta$-D-glucosaminidase (a), and independently by Paenibacillus sp. TKU052 chitinase (b), and S. speibonae TKU048 N-acetyl- $\beta$-D-glucosaminidase (c). The error bar indicates the standard deviation of three replicates.

Table 4. Comparison of enzymatic GlcNAc production by different microbial chitinases.

\begin{tabular}{|c|c|c|c|c|}
\hline Enzyme & Substrate & Time Consumed & Yield $(\%)$ & Ref. \\
\hline $\begin{array}{l}\text { Paenibacillus sp. TKU052 chitinase and } \\
\text { S. speibonae TKU048 } \\
N \text {-acetyl- } \beta \text {-D-glucosaminidase }\end{array}$ & $\mathrm{CC}$ & $12-24 \mathrm{~h}$ & $94.35-98.60$ & $\begin{array}{l}\text { This } \\
\text { study }\end{array}$ \\
\hline $\begin{array}{l}\text { S. speibonae TKU048 } \\
N \text {-acetyl- } \beta \text {-D-glucosaminidase }\end{array}$ & $\beta$-chitin powder & $96 \mathrm{~h}$ & 73.64 & [20] \\
\hline $\begin{array}{l}\text { Serratia marcescens chitinases (SmChiA, } \\
\text { SmChiB, and SmChiC) and Ostrinia furnacalis } \\
N \text {-acetyl-d-glucosaminidase (OfHex1) }\end{array}$ & Asperillus niger mycelia powder & $24 \mathrm{~h}$ & 93 & [22] \\
\hline $\begin{array}{l}\text { Streptomyces coelicolor A3(2) chitinase C } \\
\text { (ScChiC) and } N \text {-acetylhexosaminidase (ScHEX) }\end{array}$ & Crystalline chitin & $8 \mathrm{~h}$ & 90 & [54] \\
\hline $\begin{array}{l}\text { Chitinolyticbacter meiyuanensis SYBC-H1 } \\
\text { chitinase (CmChi1) }\end{array}$ & $\mathrm{CC}$ & $24 \mathrm{~h}$ & 98 & [5] \\
\hline C. meiyuanensis SYBC-H1 chitinase & Chitin powder & 4 days & near 100 & [55] \\
\hline $\begin{array}{l}\text { Myceliophthora thermophila } \mathrm{C} 1 \\
\beta-N \text {-acetylglucosaminidase (MthNAG) and } \\
\text { chitinase Chi1 }\end{array}$ & Swollen chitin & $24 \mathrm{~h}$ & 37.8 & [56] \\
\hline Aspergillus terreus chitinase & $\begin{array}{l}\text { Ground prawn shell } \\
\text { Chitin flakes } \\
\text { Colloidal prawn shell } \\
\text { Swollen chitin }\end{array}$ & 5 days & $\begin{array}{l}30 \\
73 \\
80 \\
92\end{array}$ & [57] \\
\hline Aeromonas sp. PTCC1691 crude enzyme & $\mathrm{CC}$ & $24 \mathrm{~h}$ & 79 & [58] \\
\hline Aeromonas caviae $\mathrm{CHZ306}$ enzyme cocktail & $\mathrm{CC}$ & $6 \mathrm{~h}$ & 90 & [59] \\
\hline Aeromonas sp. GJ-18 crude enzyme & Swollen chitin & 5-9 days & $83.0-94.9$ & [60] \\
\hline $\begin{array}{l}\text { P. barengoltzii } \beta \text { - } N \text {-acetylglucosaminidase } \\
\text { (PbNag39) and chitinase (PbChi70) }\end{array}$ & $\begin{array}{l}\text { Powdery chitin } \\
\text { CC }\end{array}$ & $24 \mathrm{~h}$ & $\begin{array}{l}75.3 \\
97.0\end{array}$ & [61] \\
\hline $\begin{array}{l}\text { P. barengoltzii chitinase }(\mathrm{PbChi74}) \text { and } \\
\text { Rhizomucor miehei } \beta-\mathrm{N} \text {-acetylglucosaminidase } \\
\text { (RmNAG) }\end{array}$ & $\mathrm{CC}$ & $24 \mathrm{~h}$ & 92.6 & [2] \\
\hline P. illinoisensis KJA-424 crude enzyme & Swollen chitin & $24 \mathrm{~h}$ & 62.2 & [62] \\
\hline $\begin{array}{l}\text { Streptomyces alfalae } \beta \text { - } N \text {-acetylhexosaminidase } \\
\text { (SaHEX) and a commercial chitinase (SgCtn) }\end{array}$ & CC & $6 \mathrm{~h}$ & 93.7 & [63] \\
\hline $\begin{array}{l}\text { Streptomyces violascens } \\
\beta \text {-N-acetylglucosaminidases (SvNag2557 and } \\
\text { SvNag4755) }\end{array}$ & $\begin{array}{c}\text { CC } \\
\text { Ionic liquid pretreated chitin }\end{array}$ & & $\begin{array}{l}80.2 \\
73.8\end{array}$ & [64] \\
\hline
\end{tabular}




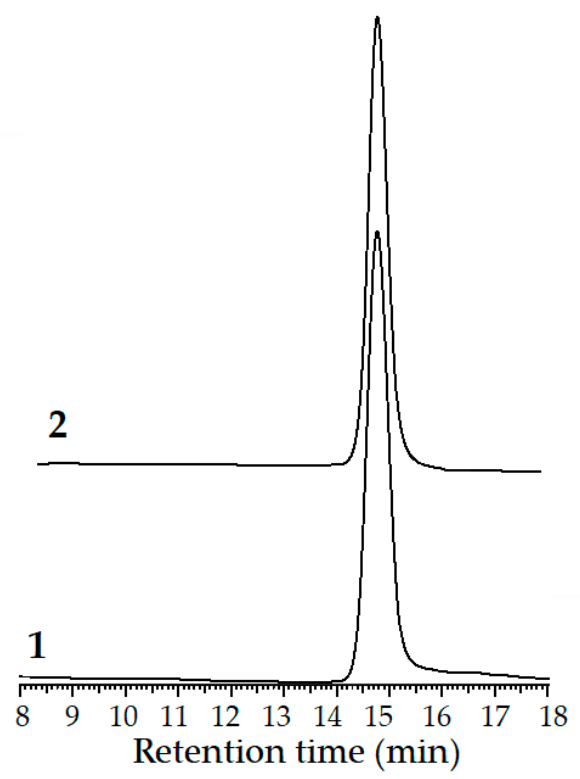

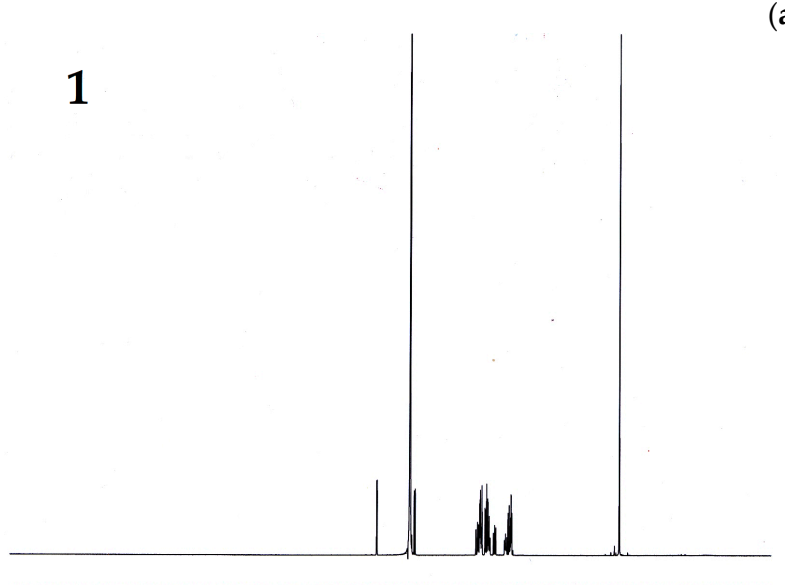

$\begin{array}{lllllllllllllllllllllllllllll}9.5 & 9.0 & 8.5 & 8.0 & 7.5 & 7.0 & 6.5 & 6.0 & 5.5 & 5.0 & 4.5 & 4.0 & 3.5 & 3.0 & 2.5 & 2.0 & 1.5 & 1.0 & \mathrm{ppm}\end{array}$

(a)

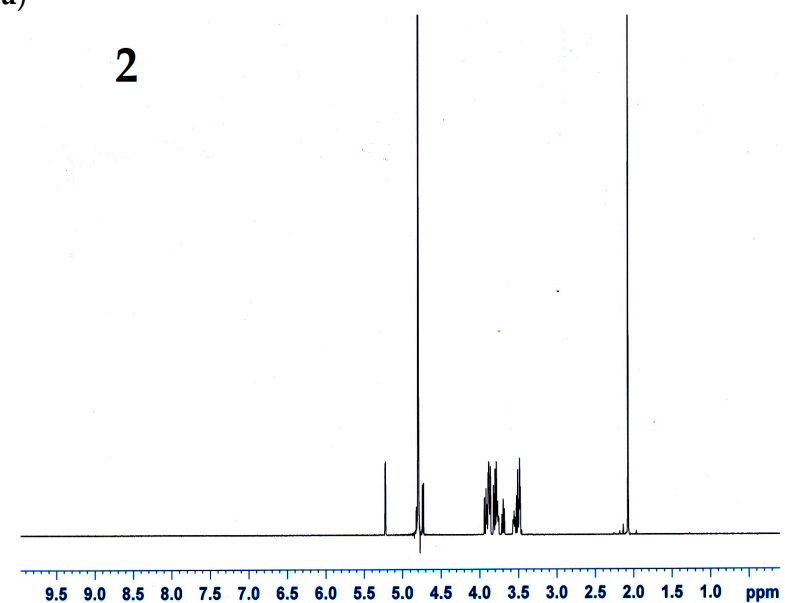

(b)

Figure 8. HPLC (a) and ${ }^{1} \mathrm{H}-\mathrm{NMR}$ (b) profiles of the obtained and commercial GlcNAc (1, obtained GlcNAc; 2 , commercial GlcNAc).

\section{Conclusions}

The exploitation of CFWs to obtain high-quality products through microbial fermentation is increasing gradually. In this study, deCSP was found to be the best potential $\mathrm{C} / \mathrm{N}$ source for chitinase production by Paenibacillus sp. TKU052 among several CFWs, and a chitinase with an MW of $72 \mathrm{kDa}$ was purified from the $0.5 \%$ deCSP-containing medium. Interestingly, the pure chitinase exhibited some valuable properties, such as high catalytic function at acidic $\mathrm{pH}$ and elevated-temperature conditions $\left(\mathrm{pH}=4-5\right.$, and $\left.70^{\circ} \mathrm{C}\right)$, and can also carry out multi-functional (exochitinase, endochitinase, and $N$-acetyl- $\beta$-Dglucosaminidase) activities. These characteristics make Paenibacillus sp. TKU052 chitinase a promising candidate for the saccharification of chitin under mild conditions. Remarkably, the coupling of Paenibacillus sp. TKU052 chitinase and S. speibonae TKU048 N-acetyl- $\beta$-Dglucosaminidase could efficiently improve the GlcNAc production from CC with a yield of $94.35-98.60 \%$ in $12-24 \mathrm{~h}$. As a result, the bioprocessing of deCSP by Paenibacillus sp. TKU052 may be potentially useful in producing chitinase as a tool for the bioconversion of chitin to GlcNAc. 
Author Contributions: Conceptualization, C.T.D. and S.-L.W.; methodology, C.T.D., T.N.T. and S.-L.W.; software, C.T.D. and T.N.T.; validation, C.T.D., T.N.T. and S.-L.W.; formal analysis, C.T.D., T.N.T. and S.-L.W.; investigation, C.T.D., T.N.T. and S.-L.W.; resources, S.-L.W.; data curation, C.T.D., T.N.T. and S.-L.W.; writing-original draft preparation, C.T.D.; writing-review and editing, C.T.D., T.N.T. and S.-L.W.; visualization, C.T.D., T.N.T. and S.-L.W.; supervision, S.-L.W.; project administration, S.-L.W.; funding acquisition, S.-L.W. All authors have read and agreed to the published version of the manuscript.

Funding: This study was supported in part by a grant from the Ministry of Science and Technology, Taiwan (MOST 109-2313-B-032-002-; MOST 110-2320-B-032-001; MOST 110-2923-B-032-001-; MOST 110-2811-B-032-001).

Institutional Review Board Statement: Not applicable.

Informed Consent Statement: Not applicable.

Data Availability Statement: The data presented in this study are available on request from the corresponding author.

Conflicts of Interest: The authors declare no conflict of interest.

\section{References}

1. Liu, C.; Shen, N.; Wu, J.; Jiang, M.; Shi, S.; Wang, J.; Wei, Y.; Yang, L. Cloning, expression and characterization of a chitinase from Paenibacillus chitinolyticus strain UMBR 0002. PeerJ 2020, 8, e8964. [CrossRef]

2. Fu, X.; Yan, Q.; Yang, S.; Yang, X.; Guo, Y.; Jiang, Z. An acidic, thermostable exochitinase with $\beta$ - $N$-acetylglucosaminidase activity from Paenibacillus barengoltzii converting chitin to N-acetyl glucosamine. Biotechnol. Biofuels 2014, 7, 174. [CrossRef] [PubMed]

3. Yadav, M.; Goswami, P.; Paritosh, K.; Kumar, M.; Pareek, N.; Vivekanand, V. Seafood waste: A source for preparation of commercially employable chitin/chitosan materials. Bioresources 2019, 6, 8-28. [CrossRef]

4. Santos, V.P.; Marques, N.S.S.; Maia, P.C.S.V.; Lima, M.A.B.d.; Franco, L.d.O.; Campos-Takaki, G.M.d. Seafood waste as attractive source of chitin and chitosan production and their applications. Int. J. Mol. Sci. 2020, 21, 4290. [CrossRef] [PubMed]

5. Zhang, A.; He, Y.; Wei, G.; Zhou, J.; Dong, W.; Chen, K.; Quyang, P. Molecular characterization of a novel chitinase CmChi1 from Chitinolyticbacter meiyuanensis SYBC-H1 and its use in N-acetyl-d-glucosamine production. Biotechnol. Biofuels 2018, 11, 179. [CrossRef] [PubMed]

6. Deng, J.J.; Zhang, M.S.; Li, Z.W.; Lu, D.L.; Mao, H.H.; Zhu, M.J.; Li, J.Z.; Luo, X.C. One-step processing of shrimp shell waste with a chitinase fused to a carbohydrate-binding module. Green Chem. 2020, 22, 6862-6873. [CrossRef]

7. Wang, C.H.; Doan, C.T.; Nguyen, V.B.; Nguyen, A.D.; Wang, S.L. Reclamation of fishery processing waste: A mini-review. Molecules 2019, 24, 2234. [CrossRef]

8. Doan, C.T.; Tran, T.N.; Nguyen, V.B.; Vo, T.P.K.; Nguyen, A.D.; Wang, S.L. Chitin extraction from shrimp waste by liquid fermentation using an alkaline protease-producing strain, Brevibacillus parabrevis. Int. J. Biol. Macromol. 2019, 131, 706-715. [CrossRef] [PubMed]

9. Doan, C.T.; Tran, T.N.; Nguyen, V.B.; Nguyen, A.D.; Wang, S.-L. Utilization of seafood processing by-products for production of proteases by Paenibacillus sp. TKU052 and their application in biopeptides' preparation. Mar. Drugs 2020, 18, 574. [CrossRef]

10. Nguyen, T.H.; Wang, S.L.; Nguyen, D.N.; Nguyen, A.D.; Nguyen, T.H.; Doan, M.D.; Ngo, V.A.; Doan, C.T.; Kuo, Y.H.; Nguyen, V.B. Bioprocessing of marine chitinous wastes for the production of bioactive prodigiosin. Molecules 2021, 26, 3138. [CrossRef]

11. Das, S.; Roy, D.; Sen, R. Utilization of chitinaceous wastes for the production of chitinase. Adv. Food Nutr. Res. 2016, 78, 27-46. [PubMed]

12. Tran, T.N.; Doan, C.T.; Nguyen, V.B.; Nguyen, A.D. The isolation of chitinase from Streptomyces thermocarboxydus and its application in the preparation of chitin oligomers. Res. Chem. Intermed. 2019, 45, 727-742. [CrossRef]

13. Wang, S.L.; Yu, H.T.; Tsai, M.H.; Doan, C.T.; Nguyen, V.B.; Do, V.C.; Nguyen, A.D. Conversion of squid pens to chitosanases and dye adsorbents via Bacillus cereus. Res. Chem. Intermed. 2018, 44, 4903-4911. [CrossRef]

14. Doan, C.T.; Tran, T.N.; Nguyen, M.T.; Nguyen, V.B.; Nguyen, A.D.; Wang, S.L. Anti- $\alpha$-glucosidase activity by a protease from Bacillus licheniformis. Molecules 2019, 24, 691. [CrossRef] [PubMed]

15. Liang, T.W.; Tseng, S.C.; Wang, S.L. Production and characterization of antioxidant properties of exopolysaccharides from Paenibacillus mucilaginosus TKU032. Mar. Drugs 2016, 14, 40. [CrossRef] [PubMed]

16. Hsu, C.H.; Nguyen, A.D.; Chen, Y.W.; Wang, S.L. Tyrosinase inhibitors and insecticidal materials produced by Burkholderia cepacia using squid pen as the sole carbon and nitrogen source. Res. Chem. Intermed. 2014, 40, 2249-2258. [CrossRef]

17. Nguyen, V.B.; Wang, S.L. Reclamation of marine chitinous materials for the production of $\alpha$-glucosidase inhibitors via microbial conversion. Mar. Drugs 2017, 15, 350. [CrossRef] [PubMed]

18. Liang, T.W.; Wu, C.C.; Cheng, W.T.; Chen, Y.C.; Wang, C.L.; Wang, I.L.; Wang, S.L. Exopolysaccharides and antimicrobial biosurfactants produced by Paenibacillus macerans TKU029. Appl. Biochem. Biotechnol. 2014, 172, 933-950. [CrossRef] [PubMed] 
19. Shereena, E.K.; Nisha, M.K.; Gaayathiri Devi, E. Chitinase production by Aspergillus terreus from marine wastes and its efficacy in antifungal activity. Int. J. Adv. Res. 2020, 8, 1399-1404.

20. Chen, J.K.; Shen, C.R.; Liu, C.L. N-acetylglucosamine: Production and applications. Mar. Drugs 2010, 8, 2493-2516. [CrossRef]

21. Tran, T.N.; Doan, C.T.; Nguyen, M.T.; Nguyen, V.B.; Vo, T.P.K.; Nguyen, A.D.; Wang, S.L. An exochitinase with $N$-acetyl- $\beta$ glucosaminidase-like activity from shrimp head conversion by Streptomyces speibonae and its application in hydrolyzing $\beta$-chitin powder to produce $N$-acetyl-D-glucosamine. Polymers 2019, 11, 1600. [CrossRef]

22. Zhu, W.; Wang, D.; Liu, T.; Yang, Q. Production of N-Acetyl-d-glucosamine from mycelial waste by a combination of bacterial chitinases and an insect $N$-acetyl-D-glucosaminidase. J. Agric. Food Chem. 2016, 64, 6738-6744. [CrossRef]

23. Salas-Ovilla, R.; Gálvez-López, D.; Vázquez-Ovando, A.; Salvador-Figueroa, M.; Rosas-Quijano, R. Isolation and identification of marine strains of Stenotrophomona maltophilia with high chitinolytic activity. PeerJ. 2019, 7, e6102. [CrossRef]

24. Bhattacharya D, Nagpure A, Gupta RK: Bacterial chitinases: Properties and potential. Crit. Rev. Biotechnol. 2007, 27, 21-28. [CrossRef]

25. Dahiya, N.; Tewari, R.; Hoondal, G.S. Biotechnological aspects of chitinolytic enzymes: A review. Appl. Microbiol. Biotechnol. 2006, 71, 773-782. [CrossRef]

26. Ben Rebah, F.; Miled, N. Fish processing wastes for microbial enzyme production: A review. 3 Biotech 2013, 3, 255-265. [CrossRef] [PubMed]

27. Ghorbel-Bellaaj, O.; Manni, L.; Jellouli, K.; Hmidet, N.; Nasri, M. Optimization of protease and chitinase production by Bacillus cereus SV1 on shrimp shell waste using statistical experimental design. Biochemical and molecular characterization of the chitinase. Ann. Microbiol. 2021, 62, 1255-1268. [CrossRef]

28. Wang, S.L.; Li, J.Y.; Liang, T.W.; Hsieh, J.L.; Tseng, W.N. Conversion of shrimp shell by using Serratia sp. TKU017 fermentation for the production of enzymes and antioxidants. J. Microbiol. Biotechnol. 2010, 20, 117-126. [CrossRef] [PubMed]

29. Cheba, B.A.; Zaghloul, T.I.; El-Mahdy, A.R. Demineralized crab and shrimp shell powder: Cost effective medium for Bacillus Sp. R2 growth and chitinase production. Procedia Manuf. 2018, 22, 413-419. [CrossRef]

30. Doan, C.T.; Tran, T.N.; Nguyen, V.B.; Tran, T.D.; Nguyen, A.D.; Wang, S.-L. Bioprocessing of squid pens waste into chitosanase by Paenibacillus sp. TKU047 and its application in low-molecular weight chitosan oligosaccharides production. Polymers 2020, 12, 1163. [CrossRef] [PubMed]

31. Wang, S.L.; Hsu, W.H.; Liang, T.W. Conversion of squid pen by Pseudomonas aeruginosa K187 fermentation for the production of $\mathrm{N}$-acetyl chitooligosaccharides and biofertilizers. Carbohydr. Res. 2010, 345, 880-885. [CrossRef] [PubMed]

32. Tariq, A.L.; Sarath Chandran, R.; Reyaz, A.L. Extracellular chitinolytic enzyme producing Paenibacillus elgii TS33 isolated from shrimp shell waste. Int. J. Pharma. Res. Health Sci. 2017, 5, 2064-2069.

33. Kim, Y.H.; Park, S.K.; Hur, J.Y.; Kim, Y.C. Purification and characterization of a major extracellular chitinase from a biocontrol bacterium, Paenibacillus elgii HOA73. Plant Pathol. J. 2017, 33, 318-328. [CrossRef]

34. Lee, D.H.; Doan, C.T.; Tran, T.N.; Nguyen, V.B.; Nguyen, A.D.; Wang, C.L.; Wang, S.L. Proteases production and chitin preparation from the liquid fermentation of chitinous fishery by-products by Paenibacillus elgii. Mar. Drugs 2021, 19, 477. [CrossRef]

35. Doan, C.T.; Tran, T.N.; Nguyen, V.B.; Nguyen, A.D.; Wang, S.L. Conversion of squid pens to chitosanases and proteases via Paenibacillus sp. TKU042. Mar. Drugs 2018, 16, 83. [CrossRef]

36. Nguyen, V.B.; Nguyen, D.N.; Nguyen, A.D.; Ngo, V.A.; Ton, T.Q.; Doan, C.T.; Pham, T.P.; Tran, T.P.H.; Wang, S.L. Utilization of crab waste for cost-effective bioproduction of prodigiosin. Mar. Drugs 2020, 18, 523. [CrossRef]

37. Seo, D.J.; Lee, Y.S.; Kim, K.Y.; Jung, W.J. Antifungal activity of chitinase obtained from Paenibacillus ehimensis MA2012 against conidial of Collectotrichum gloeosporioides in vitro. Microb. Pathog. 2016, 96, 10-14. [CrossRef]

38. Yahiaoui, M.; Laribi-Habchi, H.; Bouacem, K.; Asmani, K.L.; Mechri, S.; Harir, M.; Bendif, H.; Fertas, R.A.E.; Jaouadi, B. Purification and biochemical characterization of a new organic solvent-tolerant chitinase from Paenibacillus timonensis strain LK-DZ15 isolated from the Djurdjura Mountains in Kabylia, Algeria. Carbohydr. Res. 2019, 483, 107747. [CrossRef] [PubMed]

39. Guo, X.; Xu, P.; Zong, M.; Lou, W. Purification and characterization of alkaline chitinase from Paenibacillus pasadenensis CS0611. Chin. J. Catal. 2017, 38, 665-672. [CrossRef]

40. Ueda, J.; Kurosawa, N. Characterization of an extracellular thermophilic chitinase from Paenibacillus thermoaerophilus strain TC22-2b isolated from compost. World J. Microbiol. Biotechnol. 2015, 31, 135-143. [CrossRef] [PubMed]

41. Sun, H.; Mao, X.; Guo, N.; Zhao, L.; Cao, R.; Liu, Q. Discovery and characterization of a novel chitosanase from Paenibacillus dendritiformis by phylogeny-based enzymatic product specificity prediction. J. Agric. Food Chem. 2018, 66, 4645-4651. [CrossRef]

42. Doan, C.T.; Tran, T.N.; Nguyen, V.B.; Nguyen, A.D.; Wang, S.L. Reclamation of marine chitinous materials for chitosanase production via microbial conversion by Paenibacillus macerans. Mar. Drugs 2018, 16, 429. [CrossRef]

43. Loni, P.P.; Patil, J.U.; Phugare, S.S.; Bajekal, S.S. Purification and characterization of alkaline chitinase from Paenibacillus pasadenensis NCIM 5434. J. Basic Microbiol. 2014, 54, 1080-1089. [CrossRef] [PubMed]

44. Mathew, G.M.; Madhavan, A.; Arun, K.B.; Sindhu, R.; Binod, P.; Singhania, R.R.; Sukumaran, R.K.; Pandey, A. Thermophilic chitinases: Structural, functional and engineering attributes for industrial applications. Appl. Biochem. Biotechnol. 2021, 193, 142-164. [CrossRef] [PubMed] 
45. Doan, C.T.; Tran, T.N.; Nguyen, V.B.; Nguyen, A.D.; Wang, S.L. Production of a thermostable chitosanase from shrimp heads via Paenibacillus mucilaginosus TKU032 conversion and its application in the preparation of bioactive chitosan oligosaccharides. Mar. Drugs 2019, 17, 217. [CrossRef] [PubMed]

46. Zitouni, M.; Fortin, M.; Scheerle, R.K.; Letzel, T.; Matteau, D.; Rodrigue, S.; Brzezinski, R. Biochemical and molecular characterization of a thermostable chitosanase produced by the strain Paenibacillus sp. 1794 newly isolated from compost. Appl. Microbiol. Biotechnol. 2013, 97, 5801-5813. [CrossRef]

47. Zhang, W.; Ma, J.; Yan, Q.; Jiang, Z.; Yang, S. Biochemical characterization of a novel acidic chitinase with antifungal activity from Paenibacillus xylanexedens Z2-4. Int. J. Biol. Macromol. 2021, 182, 1528-1536. [CrossRef]

48. Jung, W.J.; Kuk, J.K.; Kim, K.Y.; Kim, T.H.; Park, R.D. Purification and characterization of chitinase from Paenibacillus illinoisensis KJA-424. J. Microbiol. Biotechnol. 2005, 15, 274-280.

49. Fu, X.; Yan, Q.; Wang, J.; Yang, S.; Jiang, Z. Purification and biochemical characterization of novel acidic chitinase from Paenibacillus barengoltzii. Int. J. Biol. Macromol. 2016, 91, 973-979. [CrossRef]

50. Singh, A.K.; Mehta, G.; Chhatpar, H.S. Optimization of medium constituents for improved chitinase production by Paenibacillus sp. D1 using statistical approach. Lett. Appl. Microbiol. 2009, 49, 708-714. [CrossRef]

51. Meena, S.; Gothwal, R.K.; Saxena, J.; Nehra, S.; Mohan, M.K.; Ghosh, P. Effect of metal ions and chemical compounds on chitinase produced by a newly isolated thermotolerant Paenibacillus sp. BISR-047 and its shelf-life. Int. J. Curr. Microbiol. Appl. Sci. 2015, 4, 872-881.

52. Alves, T.B.; de Oliveira Ornela, P.H.; de Oliveira, A.H.C.; Jorge, J.A.; Guimarães, L.H.S. Production and characterization of a thermostable antifungal chitinase secreted by the filamentous fungus Aspergillus niveus under submerged fermentation. 3 Biotech 2018, 8, 369. [CrossRef]

53. Yang, S.; Fu, X.; Yan, Q.; Guo, Y.; Liu, Z.; Jiang, Z. Cloning, expression, purification and application of a novel chitinase from a thermophilic marine bacterium Paenibacillus barengoltzii. Food Chem. 2016, 192, 1041-1048. [CrossRef]

54. Nguyen-Thi, N.; Doucet, N. Combining chitinase C and N-acetylhexosaminidase from Streptomyces coelicolor A3(2) provides an efficient way to synthesize $N$-acetylglucosamine from crystalline chitin. J. Biotechnol. 2016, 220, 25-32. [CrossRef] [PubMed]

55. Zhang, A.; Gao, C.; Wang, J.; Chen, K.; Quyang, P. An efficient enzymatic production of N-acetyl-D-glucosamine from crude chitin powders. Green Chem. 2016, 18, 2147-2154. [CrossRef]

56. Krolicka, M.; Hinz, S.W.A.; Koetsier, M.J.; Eggink, G.; van den Broek, L.A.M.; Boeriu, C.G. $\beta$-N-Acetylglucosaminidase MthNAG from Myceliophthora thermophila C1, a thermostable enzyme for production of $N$-acetylglucosamine from chitin. Appl. Microbiol. Biotechnol. 2018, 102, 7441-7454. [CrossRef] [PubMed]

57. Das, S.; Dey, P.; Roy, D.; Maiti, M.K.; Sen, R. N-Acetyl-D-glucosamine production by a chitinase of marine fungal origin: A case study of potential industrial significance for valorization of waste chitins. Appl. Biochem. Biotechnol. 2019, 187, 407-423. [CrossRef]

58. Jamialahmadi, K.; Behravan, J.; Fathi Najafi, M.; Tabatabaei Yazdi, M.; Shahverdi, A.R.; Faramarzi, M.A. Enzymatic production of N-Acetyl-D-glucosamine from chitin using crude enzyme preparation of Aeromonas sp. PTCC1691. Biotechnology 2011, 10, 292-297. [CrossRef]

59. Cardozo, F.A.; Facchinatto, W.M.; Colnago, L.A.; Campana-Filho, S.P.; Pessoa, A. Bioproduction of N-acetyl-glucosamine from colloidal $\alpha$-chitin using an enzyme cocktail produced by Aeromonas caviae CHZ306. World J. Microbiol. Biotechnol. 2019, 35, 114. [CrossRef]

60. Kuk, J.H.; Jung, W.J.; Jo, G.H.; Kim, Y.C.; Kim, K.Y.; Park, R.D. Production of N-acetyl-beta-D-glucosamine from chitin by Aeromonas sp. GJ-18 crude enzyme. Appl. Microbiol. Biotechnol. 2005, 68, 384-389. [CrossRef]

61. Liu, Y.; Jiang, Z.; Ma, J.; Ma, S.; Yan, Q.; Yang, S. Biochemical characterization and structural analysis of a $\beta-N-$ acetylglucosaminidase from Paenibacillus barengoltzii for efficient production of $N$-acetyl-d-glucosamine. J. Agric. Food Chem. 2020, 68, 5648-5657. [CrossRef] [PubMed]

62. Jung, W.J.; Souleimanov, A.; Park, R.D.; Smith, D.L. Enzymatic production of $N$-acetyl chitooligosaccharides by crude enzyme derived from Paenibacillus illioisensis KJA-424. Carbohydr. Polym. 2007, 67, 256-259. [CrossRef]

63. Lv, C.; Gu, T.; Xu, K.; Gu, J.; Li, L.; Liu, X.; Zhang, A.; Gao, S.; Li, W.; Zhao, G. Biochemical characterization of a $\beta-N$ acetylhexosaminidase from Streptomyces alfalfae and its application in the production of N-acetyl-D-glucosamine. J. Biosci. Bioeng. 2019, 128, 135-141. [CrossRef] [PubMed]

64. Li, J.; Gao, K.; Secundo, F.; Mao, X. Biochemical characterization of two $\beta$-N-acetylglucosaminidases from Streptomyces violascens for efficient production of $N$-acetyl-d-glucosamine. Food Chem. 2021, 364, 130393. [CrossRef] [PubMed] 